\section{USDA, ARS Cucumis hystrix-derived U.S. Processing Cucumber Inbred Backcross Line Population}

\author{
Jack E. Staub ${ }^{1,2}$ and Isabelle Y. Delannay ${ }^{1}$ \\ Vegetable Crops Research, U.S. Department of Agriculture, Agricultural \\ Research Service, Department of Horticulture, University of Wisconsin, \\ Madison, WI 53706

\section{Jin-Feng Chen \\ State Key Laboratory of Crop Genetics and Germplasm Enhancement, Key Laboratory of Southern Vegetable Crop Genetic Improvement, Nanjing Agricultural University, Nanjing, 210095 China}

Additional index words. Cucumis sativus, genetic distance, vegetable breeding var. sativus $\mathrm{L}$.; $2 \mathrm{n}=2 \mathrm{x}=14$ ) is extremely narrow $\{3 \%$ to $8 \%$ among elite and exotic germplasm and $12 \%$ between botanical varieties [C. sativus var. sativus $\mathrm{L}$. and var. hardwickii (R.) Alef.]\} (Dijkhuizen et al., 1996; Horejsi and Staub, 1999). In fact, the limited genetic diversity of U.S. processing cucumber (especially since 1950) may, in part, be the result of the broad use of only a few cultigens (e.g., line Gy-14) in cultivar development (Staub et al., 2008). Yield in processing cucumber has plateaued in the last 20 years, and the introgression of exotic genes into commercial cucumber may provide opportunities for germplasm enhancement. Therefore, a series of 94 C. hystrix Chakr.-derived U.S. processing market-type inbred backcross lines (IBL) were released in Jan. 2011 by the Agricultural Research Service, U.S. Department of Agriculture to provide genetic stocks for broadening the genetic base of pickling cucumber. The IBL were developed by crossing a U.S. processing cucumber (C. sativus L.; line WI 7023A) and a $C$. hystrix-derived (C. hystrix $\times C$. sativus) U.S. cucumber breeders to supply a source from which they may develop processing market types with increased genetic diversity and yield potential suitable for field production.
The genetic base of cucumber (C. sativus line (WI 7012A) and is made available to
Received for publication 31 Jan. 2011. Accepted for publication 11 Apr. 2011.

Mention of a trade name, proprietary product, or specific equipment does not constitute a guarantee or warranty by the USDA and does not imply its approval to the exclusion of other products that may be suitable. Agricultural Research Service, Forage and Range Research Laboratory, Utah State University, 696 E. 1100 N., Logan, UT 84322-6300.

${ }^{2}$ To whom reprint requests should be addressed; e-mail jack.staub@ars.usda.gov.
${ }^{1}$ Currently at the U.S. Department of Agriculture, pollination to produce the $\mathrm{BC}_{2} \mathrm{~S}_{1}$ generation followed by single-seed descent to generate 94 $\mathrm{BC}_{2} \mathrm{~S}_{3}$ IBLs (Tanksley et al., 1996; Wehrhahn and Allard, 1965).

The relatively high-yielding, multiple lateral branching, gynoecious, determinate line WI 7023A produces warty, light-green fruit of commercially acceptable shape and quality (Fig. 1). It was created by mating line Gy7 (synom. G421) and line H-19, which were originally obtained from the University of Wisconsin Madison (Madison, WI) and the University of Arkansas (Fayetteville, AR), respectively. Line WI 7023A was created through selection and backcrossing with Gy7 as the recurrent parent and $\mathrm{H} 19$ as the donor parent $\left(\mathrm{BC}_{4} \mathrm{~S}_{3}\right)$ to identify a small-statured genotype for once-over mechanical harvest operations. It originated from the same populations that were used to develop recombinant inbred lines for the mapping of quantitative trait loci in U.S. processing cucumber (Fazio

The late-flowering, indeterminate, monoecious line WI $7012 \mathrm{~A}$ is a $\mathrm{BC}_{1} \mathrm{~S}_{3}$ line derived from a cross between the amphidiploid $C$. hystivus $(2 \mathrm{n}=2 \mathrm{x}=24$; Chen and Kirkbride, 2000) and the $C$. sativus longfruited Chinese cultivar Beijingjietou (recurrent backcross parent; $2 \mathrm{n}=2 \mathrm{x}=14$ ) mating (Chen et al., 2003). C. hystivus originated through the chromosome doubling of an infertile $\mathrm{F}_{1}(C$. hystrix $\times C$. sativus; $2 \mathrm{n}=2 \mathrm{x}=$ $19)$ individual to produce a fertile amphidiploid $(2 \mathrm{n}=4 \mathrm{x}=38)$ as identified during in vitro embryo culture (Chen et al., 1998, 2003; Chun-Tao et al., 2005). The amphidiploid was backcrossed to Beijingjietou to produce viable seed without further manipulation (i.e., et al., 2003; Staub et al., 2002). mately eight seeds of each $\mathrm{BC}_{2}$ line $(8 * 25=$ 200 total) were randomly selected for self-

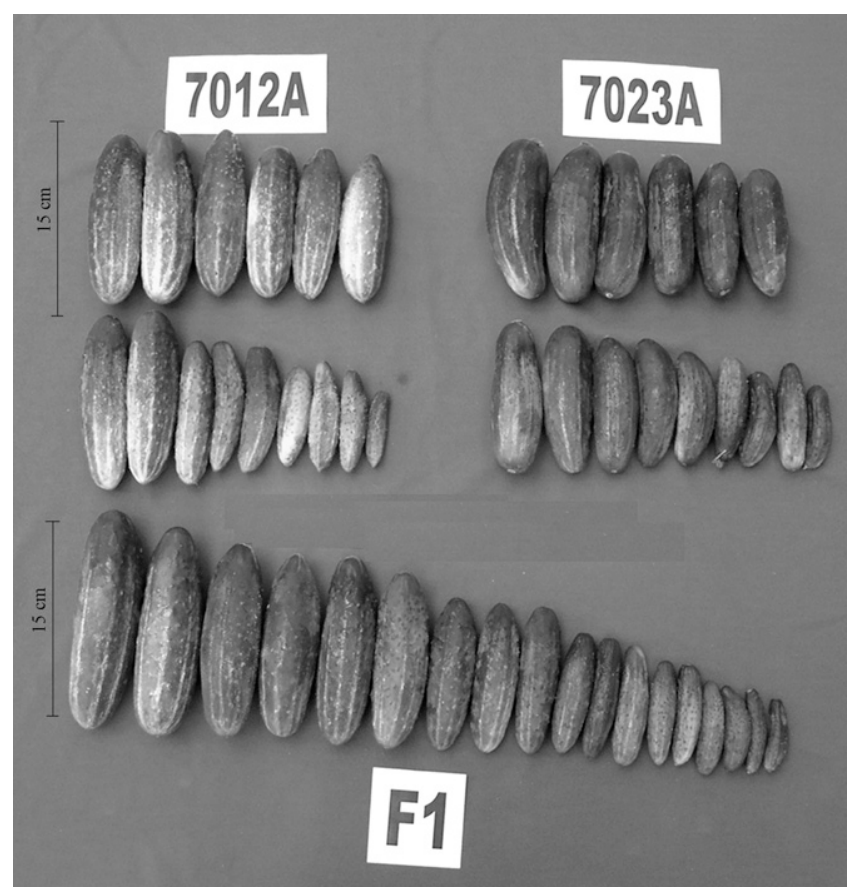

Fig. 1. Fruit of determinate U.S. processing cucumber (Cucumis sativus L.; recurrent parent) line WI 7023A, indeterminate $C$. hystrix Chakr.-derived [ $($ C. hystrix $\times$ C. sativus $) \times C$. sativus; donor parent] $\mathrm{BC}_{1} \mathrm{~S}_{3}$ line WI $7012 \mathrm{~A}$, and their derived indeterminate $\mathrm{F}_{1}$ progeny used in backcrossing and as observed at Hancock, WI, during the summer of 2007. 
Table 1. Combined early and late planting means, sDS, and ranges of traits of parents [WI 7023A (recurrent parent, Cucumis sativus L.) and WI 7012A (donor parent, C. hystivus derived)] and their derived cucumber (C. sativus $\mathrm{L}$.) inbred backcross lines $\left(\mathrm{BC}_{2} \mathrm{~S}_{3}\right)$ as evaluated in 2008.

\begin{tabular}{|c|c|c|c|c|c|c|c|c|c|c|c|c|}
\hline \multirow[b]{2}{*}{ Trait $^{\mathrm{w}}$} & \multicolumn{4}{|c|}{ WI 7023 $\mathrm{A}^{\mathrm{z}}$} & \multicolumn{4}{|c|}{ WI 7012A } & \multicolumn{4}{|c|}{$\mathrm{IBL}^{\mathrm{x}}$} \\
\hline & $\overline{\text { Mean }^{v}}$ & SD & Minimum & Maximum & Mean & SD & Minimum & $\overline{\text { Maximum }}$ & Mean & SD & Minimum & Maximum \\
\hline$\overline{\mathrm{DA}}$ & 42.07 & 1.91 & 37.00 & 46.00 & 48.14 & 2.52 & 41.00 & 53.00 & 43.63 & 3.72 & 33.00 & 59.00 \\
\hline Sex & 2.00 & 0.00 & 2.00 & 2.00 & 0.00 & 0.00 & 0.00 & 0.00 & 1.25 & 0.97 & 0.00 & 2.00 \\
\hline LB & 0.56 & 0.81 & 0.00 & 2.00 & 3.01 & 0.96 & 1.00 & 5.00 & 2.21 & 1.38 & 0.00 & 7.00 \\
\hline LL & 0.00 & 0.00 & 0.00 & 0.00 & 0.00 & 0.00 & 0.00 & 0.00 & 0.04 & 0.18 & 0.00 & 1.00 \\
\hline Fruit per plant & 1.92 & 0.39 & 1.14 & 2.31 & 2.46 & 1.26 & 1.38 & 4.45 & 2.23 & 0.87 & 0.25 & 5.83 \\
\hline $\mathrm{L}: \mathrm{D}$ & 2.92 & 0.14 & 2.73 & 3.11 & 3.62 & 0.13 & 3.43 & 3.78 & 3.07 & 0.28 & 2.33 & 4.28 \\
\hline GD & 0.45 & 0.09 & 0.30 & 0.85 & 0.74 & 0.05 & 0.55 & 0.88 & 0.48 & 0.08 & 0.16 & 0.88 \\
\hline
\end{tabular}

${ }^{2} \mathrm{WI} 7023 \mathrm{~A}\left(\mathrm{BC}_{4} \mathrm{~S}_{3}\right)$ is a determinate, gynoecious line created through selection and backcrossing [Gy-7 (recurrent parent; University of Wisconsin) and H19 (donor parent; University of Arkansas, Fayetteville, Ark.)] to identify a small-statured genotype for once-over mechanical harvest operations (Staub et al., 2002). ${ }^{y} \mathrm{WI}$ 7012A $\left(\mathrm{BC}_{1} \mathrm{~S}_{3}\right)$ is a late-flowering, indeterminate, monoecious line derived from a C. hystivus $\times$ C. sativus (long-fruited Chinese C. sativus cultivar Beijingjietou; recurrent backcross parent) mating (Chen et al., 2003).

${ }^{\mathrm{x}}$ Combined IBL contains all 94 inbred backcross lines $\left(\mathrm{BC}_{2} \mathrm{~S}_{3}\right)$ developed by crossing WI 7023A (recurrent parent) with WI 7012A (donor parent), backcrossing twice with selection for maximum heterozygosity, and self-pollinating three times.

${ }^{\mathrm{w}} \mathrm{DA}=$ Days to anthesis recorded as the number of days between transplanting and the appearance of the first fully expanded corolla; Sex $=$ sex expression recorded as sex score in which gynoecious, predominantly female and monoecious were recorded with values of 2,1 , and 0 , respectively; LB = lateral branch number recorded as the number of lateral branches on the first 10 nodes; $L L=$ little-sized leaf $(l l)$ recorded as the percentage of plants within a line with a maximum leaf area of 30 to $40 \mathrm{~cm}^{2}$; number of fruit per plant recorded as the average number of fruit per plant within a line over three harvests; Fruit L:D = the average length (L) and diameter (D) ratio (L:D) of five to 10 fruit per plot over three harvests, and; GD = genetic distance, which was calculated as the average genetic distance using Rogers (1972) genetic distance formula as modified by Wright (1978) comparing all lines with the lines within the given group.

"Mean, sDs, minimum, and maximum values for each population within a trait.

in vitro culture). Then these progeny were selfpollinated for three generations $\left(\mathrm{BC}_{1} \mathrm{~S}_{3}\right)$, in which selection was practiced for reduced chromosome number in each generation. The result of this selection and selfing was WI 7012A $(2 \mathrm{n}=2 \mathrm{x}=14)$ (Staub et al., 2008).

\section{Description}

Multivariate analyses using Rogers (Rogers, 1972) genetic distances (GD) modified by Wright (1978) were used employing 32 codominant markers to define phenotypic and genotypic relationships between the IBL and their parents (Delannay, 2009; Delannay et al., 2010). The greatest GD was between the parental lines (0.85), whereas the GD among IBLs ranged between 0.16 and 0.75 . The most genetically similar IBL were lines 113 and 201 and lines 3 and $180(\mathrm{GD}=0.16)$. In contrast, IBL with the least genetic similarity were lines 51 and 187 $(\mathrm{GD}=0.75)$.

Marker-based selection for heterozygosity at $\mathrm{BC}_{1}$ did not eliminate the phenotypic diversity in $\mathrm{BC}_{2}$ progeny (Delannay et al., 2010). Based on replicated open-field trials conducted at Hancock, WI, during the summers of 2006 and 2007, IBLs differ in days to flower, sex expression, lateral branch number, number of fruits per plant, and fruit length and diameter ratio (Table 1; Fig. 1; Delannay et al., 2010). For instance, although IBL 206 developed the greatest number of fruit per plant (approximately four) and lateral branches (approximately four), IBL 3 provided the lowest yield (approximately one fruit per plant), IBL 38 the lowest length: diameter (L:D; 2.6), and IBL 188 required the longest time to flower [days to anthesis (DA) $\approx 50$ ]. By comparison, IBL 119 recorded the shortest time to flower $(\mathrm{DA} \approx 39)$ and IBL 226 developed fruit with the largest L:D $(\approx 3.9)$.

The genotypic and phenotypic diversity among and between IBL are not necessarily equivalent (Table 1). Although IBL 113 and
201 possess the strongest genetic similarities $(\mathrm{GD}=0.16)$, they had dramatically different morphological attributes. For instance, IBL 201 produced few lateral branches and comparatively few short fruit (zero to one laterals per plant, one to two fruit per plant, and $\mathrm{L}: \mathrm{D}=$ 2.7 to 2.9 ), and IBL 113 produced many lateral branches and many narrow fruit (approximately four laterals per plant, 3.4 fruits per plant, and $\mathrm{L}: \mathrm{D}=3.4$ ).

Many IBLs are gynoecious and lack the negative attributes associated with the monoecious WI 7012A (i.e., spiny, warty, and oblong fruit). For this and other reasons (Table 1), IBLs should be considered unique germplasm that can be used directly by plant improvement programs seeking to increase genetic diversity in cucumber. Moreover, given the consistency of phenotypic differences in IBL, they should perform consistently in early and late harvest operations typical of upper-Midwestern U.S. climates (Delannay et al., 2010).

The IBLs have been phenotypically and genotypically described (Delannay et al., 2010), and thus, can be used in cucumber improvement and genetic studies. For instance, after initial evaluation of these IBLs in specific target environments, strategic crossing of these IBLs with elite lines may allow for the development of broad- and narrow-based populations for phenotypic and/or marker-assisted selection (Fan et al., 2006). Where IBL have contrasting traits, they have use for the genetic analysis of complex traits (e.g., yield and quality components; characterization of epistatic interactions) (Robbins et al., 2008; Tanksley et al., 1996), and selected IBL (e.g., high yield, early flowering, and multiple lateral branching types) could be used in mapping experiments where synteny of quantitative trait loci controlling yield components could be assessed between $C$. sativus and $C$. hystivus genomes. Additionally, these diverse IBLs will also be useful in genetic studies and/or to evaluate cross-progeny derived from matings between $C$. hystrix and derived germplasm [e.g., amphidiploid, diploid $(2 \mathrm{n}=14) C$. hystivus $\times C$. sativus backcross derivatives] and substitution lines (Chen et al., 2004).

\section{Availability}

Seed of C. hystrix-derived IBLs from a handpollinated greenhouse increase may be obtained by addressing requests to P.W. Simon (philipp. simon@ars.usda.gov), Vegetable Crops Research, U.S. Department of Agriculture, Agricultural Research Service, Department of Horticulture, University of Wisconsin, Madison, WI 53706.

\section{Literature Cited}

Chen, J., J.E. Staub, C. Qian, J. Jiang, X. Luo, and F. Zhuang. 2003. Reproduction and cytogenetic characterization of interspecific hybrids derived from Cucumis hystrix Chakr. $\times$ Cucumis sativus L. Theor. Appl. Genet. 106:688-695.

Chen, J.F., J.W. Adelberg, J.E. Staub, H.T. Skorupska, and B.B. Rhodes. 1998. A new synthetic amphidiploid in Cucumis from C. sativus $\mathrm{L} \times C$. hystrix Chakr. $\mathrm{F}_{1}$ interspecific hybrid. In: McCreight, J.D. (ed.). Cucurbitaceae-8Evaluation and enhancement of Cucurbit germplasm. ASHS Press, Alexandria, VA.

Chen, J.F. and J.H. Kirkbride. 2000. A new synthetic species of Cucumis (Cucurbitaceae) from interspecific hybridization and chromosome doubling. Brittonia 52:315-319.

Chen, J.F., X.D. Luo, C.T. Qian, M.M. Jahn, J.E. Staub, F.Y. Zhuang, Q.F. Lou, and G. Ren. 2004. Cucumis monosomic alien addition lines: Morphological, cytological, and genotypic analyses. Theor. Appl. Genet. 108:1343-1348.

Chun-Tao, Q., M.M. Jahn, J.E. Staub, X.D. Lou, and J.F. Chen. 2005. Meiotic chromosome behavior in an allotriploid derived from an amphidiploid $\times$ diploid mating in Cucumis. Plt. Breed. 124:272-276.

Delannay, I.Y. 2009. Use of molecular markers to increase genetic diversity of Beit Alpha, European Long, and U.S. Processing market classes of cucumber (Cucumis sativus L.) through marker-assisted selection. PhD diss., University of Wisconsin at Madison, Madison, WI. 
Delannay, I.Y., J.E. Staub, and J.F. Chen. 2010. Backcross introgression of the Cucumis hystrix Chakr. genome increases genetic diversity in U.S. processing cucumber (Cucumis sativus L.). J. Amer. Soc. Hort. Sci. 135:351361.

Dijkhuizen, A., W.C. Kennard, M.J. Havey, and J.E. Staub. 1996. RFLP variation and genetic relationships in cultivated cucumber. Euphytica 90:79-87.

Fan, Z., M.D. Robbins, and J.E. Staub. 2006. Population development by phenotypic selection with subsequent marker-assisted selection for line extraction in cucumber (Cucumis sativus L.). Theor. Appl. Genet. 112:843-855.

Fazio, G., J.E. Staub, and M.R. Stevens. 2003. Genetic mapping and QTL analysis of horticultural traits in cucumber (Cucumis sativus L.) using recombinant inbred lines. Theor. Appl. Genet. 107:864-874.

Horejsi, T. and J.E. Staub. 1999. Genetic variation in cucumber (Cucumis sativus L.) as assessed by random amplified polymorphic DNA. Genet. Resources Crop Evol. 46:337-350.

Robbins, M.D., M. Casler, and J.E. Staub. 2008. Pyramiding QTL for multiple lateral branching in cucumber using nearly isogenic lines. Mol. Breed. 22:131-139.

Rogers, J.S. 1972. Measures of genetic similarity and genetic distance. Studies in Genet. VII Univ. Texas Publ. 7213. p. 145-153.

Staub, J.E., L.K. Crubaugh, and G. Fazio. 2002. Cucumber inbred lines. Cucurbit Genet. Coop. Rpt. 25:1-2.

Staub, J.E., M.D. Robbins, and T.C. Wehner. 2008. Cucumber, p. 241-282. In: Prohens, J. and F.
Nuez (eds.). Vegetables. I: Asteraceae, Brassicaceae, Chenopodiaceae, and Cucurbitaceae. Springer, New York, NY.

Tanksley, S.D., S. Grandillo, T.M. Fulton, D. Zamir, Y. Eshed, V. Petiard, J. Lopez, and T. Beck-Bunn. 1996. Advanced backcross QTL analysis in a cross between an elite processing line of tomato and its wild relative $L$. pimpinellifolium. Theor. Appl. Genet. 92:213-224.

Wehrhahn, C. and R.H. Allard. 1965. The detection and measurement of the effects of individual genes involved in the inheritance of a quantitative character in wheat. Genetics 51:109-119.

Wright, S. 1978. Evolution and the genetics of populations. Variability within and among natural populations. U. Chicago Press, Chicago, IL. 